\title{
Preoperative education for lumbar surgery for radiculopathy
}

\begin{abstract}
To date no studies have been published on preoperative education for patients who had lumbar surgery. The aim of this study was to determine if there is a demand for preoperative education for patients who had lumbar surgery for radiculopathy. A convenience sample of 47 patients who had lumbar surgery and a random sample of 141 physiotherapists involved in treating patients who had lumbar surgery completed a newly developed spinal surgery questionnaire. The data were analyzed using descriptive and inferential statistical tests. Results showed that 100\% of the patients and $99 \%$ of therapists view preoperative education to be an important component for lumbar surgery for radiculopathy. The most important factors identified for inclusion in preoperative educational programs were reason for surgery, risks associated with surgery, limitations following surgery and more education regarding pain. The preferred method of education delivery was verbal oneon-one education. This study demonstrates that there is a demand for preoperative education for patients who had lumbar surgery.

Louw A, PT, MSc
Louw Q, PT, PhD
Crous L, PT, MSc
\end{abstract}

KEYWORDS: LUMBAR; SURGERY; RADICULOPATHY; PREOPERATIVE; EDUCATION; PHY SIOTHERAPY.

\section{INTRODUCTION}

Low back pain (LBP) is considered the most prevalent musculoskeletal disorder in Western civilization (Deyo et al 2002). Although most studies have been conducted in developed countries, a recent systematic review showed that LBP is quite common in Africa and a source of constant disability (Louw et al 2007).

Spinal surgery is extremely prevalent and "ever increasing" in developed countries such as the United States (US), England, Australia and Scandinavian countries, with the likelihood of having back surgery at least $40 \%$ higher in the US than in any other country (Deyo and Mirza 2006; Lurie et al 2003). No studies are available on the rates of spinal surgery in Africa. Emerging data, however, indicates the potential for increased rates of spinal surgery in South Africa. Discovery, the largest medical aid fund in South Africa, has had a $112 \%$ increase in hospital admissions and use of magnetic resonance imaging for LBP in 2005 (Discovery Statistics 2005). This concurs with studies showing a direct correlation between increased use of high-tech imaging studies and increased prevalence of spinal surgery in those geographical areas (Lurie et al 2003). The success rate of spinal surgery for LBP is controversial with up to $40 \%$ of patients still experiencing pain and disability following spinal surgery (Deyo and Mirza et al 2006; Lurie et al 2003; Ostelo et al 2003). If persistent symptoms are present following surgery, post-surgical rehabilitation, consisting mainly of exercise in varying formats, is often prescribed to decrease pain and disability (Ostelo et al 2003). A recent Cochrane review, however, indicated that there is inconclusive evidence for the effectiveness of postsurgical rehabilitation programs (Ostelo et al 2003).

In the orthopedic domain, there are a number of studies into the effect of education on pain and disability, with outcomes ranging from "excellent" (Udermann et al 2004) to "poor" (Gross et al 2000). A recent systematic review of all preoperative education programs in the orthopedic domain found only studies relating to total knee and total hip replacements and no studies on spinal surgery populations (Johansson et al 2005). Thus, there is a lack of information on preoperative educational approaches for lumbar surgery for radiculopathy (LSR), including content, preferred delivery method and need for such programs. The objective of this 
laminotomy, laminectomy and/or discectomy for lumbar radiculopathy, and attended their first outpatient postoperative consultation with the surgeon, were eligible to participate. Exclusions included not being proficient in the English language, previous spinal surgery, decompressive surgery for conditions other than lumbar radiculopathy and other surgical interventions. Patients were recruited from five spinal surgery groups in the Greater Kansas City metropolitan area between March 1, 2006 and September 15, 2006 to represent patients in the Greater Kansas City metropolitan area.

The physiotherapists were eligible to participate if they were licensed in Kansas and Missouri and actively involved in treating patients having undergone LSR at the time of the study. Exclusions included not being proficient in the English language or having less than two years of clinical experience. One thousand physiotherapists licensed to practice in Kansas and Missouri were randomly selected by the statistician by means of a statistical program to participate in the study.

\section{Measurement Tool}

A new questionnaire was designed to serve as the measurement tool for both the patient and physiotherapist studies. A review of electronic databases was conducted to search for questionnaires on educational needs for patients. Three questionnaires were reviewed for content and format to assist in the design of the questionnaire for this study (Asilioglu and Celik 2004; Macario et al 2003). Additionally, interviews with two spine surgeons, three physiotherapists and two surgical technicians were conducted to help design the questionnaire.

To establish face and content validity, the newly developed spine surgery questionnaire was sent to a panel of 12 international experts in the field of spinal surgery rehabilitation, patient education and questionnaire design, accompanied by checklists for comments. Following the recommendations of the expert panel review, changes were made to the newly developed spine surgery questionnaire, including a pain section and minor grammatical corrections. The updated spine surgery questionnaires and checklists were then distributed to a convenience sample of five patients who had LSR in the past three weeks as well as a convenience sample of five physiotherapists actively involved with treating patients having undergone LSR. After the pilot studies no changes were required of the spine surgery questionnaire, thus deeming it ready for implementation for the main study.

The final spine surgery questionnaires were organized into three sections: Section one - instructions on completing the questionnaire; Section two - demographic information and Section three consisting of a series of 29 questions regarding educational needs, divided into five categories (Table 1). A $10 \mathrm{~cm}$ linear scale was used to rate the importance of a question being answered by the patient, ranging from "not important" to "very important." At the end of each section questions were asked to ascertain the preferred profession to deliver information in regards to that particular section. The questionnaires used for the patient and physiotherapist studies consisted of the same content, except therapists were asked to rate the impor-

Table 1: Surgery Questionnaire content.

\begin{tabular}{|l|l|}
\hline Section & Content \\
\hline 1: Surgical Procedure & $\begin{array}{l}\text { Anatomy, Pathology and } \\
\text { Surgical Technique }\end{array}$ \\
\hline 2: Medical Care & $\begin{array}{l}\text { Blood transfusion, medication preoperatively, } \\
\text { food and fluid intake preoperatively, } \\
\text { anesthesia, medical clearance from their } \\
\text { primary care physician, hospital stay, use of } \\
\text { back brace postoperatively and consultation } \\
\text { with the surgeon postoperatively }\end{array}$ \\
\hline 3: Prognosis & $\begin{array}{l}\text { Pain at the surgical site, pain "left over" after } \\
\text { the surgery, "new" pains, overall prognosis } \\
\text { and length of recovery. }\end{array}$ \\
\hline $\begin{array}{l}\text { 4: Functional activities } \\
\text { and restrictions }\end{array}$ & $\begin{array}{l}\text { Driving, lifting, bending, sitting, transfers in } \\
\text { and out of bed, walking, needing physical } \\
\text { therapy after surgery and content of } \\
\text { postoperative physical therapy. }\end{array}$ \\
\hline $\begin{array}{l}\text { 5: Education delivery } \\
\text { methods }\end{array}$ & $\begin{array}{l}\text { One-on-one education, group education, } \\
\text { videos, audiotapes and slides, color } \\
\text { pamphlets, websites and who should deliver } \\
\text { the preoperative education. }\end{array}$ \\
\hline
\end{tabular}

tance of the questions being answered for their patients based on their experience treating patients undergoing LSR.

\section{Data collection procedure}

Patients were required to attend a routine follow-up visit with the surgeon one month postoperatively. Sixty eligible patients were invited; consent was obtained and then completed the questionnaire before consultation with the surgeon. Completion of the questionnaire took approximately 10 minutes. The completed questionnaires were placed in self-sealed envelopes and handed to an independent administrative assistant. Data were collected between March 1, 2006 and September 15, 2006. Collected questionnaires were examined against inclusion/exclusion criteria, numbered and catalogued accordingly, and recorded.

To collect data from the physiotherapists, a letter describing the research study, eligibility criteria and seeking permission to participate in the study was mailed to the 1000 randomly selected participants. All therapists were asked to return the survey within 60 days (Jette et al 2003). After 30 days, a 
postcard reminder was mailed to all participants thanking them for their participation and reminding them to return their questionnaires if they had not done so (Jette et al 2003). Returned completed questionnaires were tracked on the random sampling list.

\section{Data analysis}

The data was analyzed using descriptive and inferential statistical tests.

\section{RESULTS}

\section{Demographics}

Forty seven patients completed the questionnaire. The typical patient undergoing lumbar surgery for radiculopathy was a middle aged Caucasian male or female who was well-educated, aware of the surgery they underwent and on average produced an annual income around $\$ 50000$ (US).
One hundred and forty one physiotherapists completed and returned the questionnaires. Physiotherapists treating postoperative patients for LSR could best be described as middle aged physiotherapists with a Master's degree, who have been in clinical practice for 15 years. These therapists were employed full-time in an outpatient orthopedic environment with no additional certification. The demographic data for the patients and physiotherapists is presented in Table 2.

\section{Importance of preoperative education}

All patients $(100 \% ; \mathrm{n}=47)$ and $99 \%$ $(\mathrm{n}=141)$ of physiotherapists surveyed perceived preoperative education to be important for patients undergoing LSR. On a scale of 0 (not important to know) to 100 (very important to know), patients averaged a score of 82.51 , which indicates the significant importance of questions being answered to patients prior to LSR. Main themes extracted from the patient answers included: "better knowledge and understanding of the surgical procedure and be better prepared," "need to know the risks associated with the surgery" and "decreased anxiety and fear.'

\section{Content of a preoperative education program}

The comparative ranking between the top 5 issues for patients and physiotherapists are shown in Table 3.

- Surgical Procedure: Physiotherapists rated it significantly more important $(\mathrm{p}<0.05)$ than patients to know about alternatives to the surgical procedure ( $\mathrm{p}<0.01)$. Sub-group analysis indicated that outpatient physiotherapists were more inclined to rate alternatives to surgery as important, compared to inpatient physiotherapists

Table 2: Demographic data for the patient and physiotherapist study.

\begin{tabular}{|c|c|c|c|}
\hline \multicolumn{2}{|l|}{ Patient Study } & \multicolumn{2}{|l|}{ Physiotherapist Study } \\
\hline Average age (in years) & $46.13( \pm 10.92)$ & Average age (in years) & $41.65( \pm 10.56)$ \\
\hline Sex & & Highest attained degree & \\
\hline - Male & $21(45 \%)$ & - Masters degree & $51 \%$ \\
\hline - Female & $26(55 \%)$ & - Bachelor's degree & $43 \%$ \\
\hline \multirow{5}{*}{$\begin{array}{l}\text { Ethnicity } \\
\text { - Caucasian } \\
\text { - African American } \\
\text { - Hispanic } \\
\text { - Asian }\end{array}$} & \multirow{5}{*}{$\begin{array}{l}85.11 \% \\
6.37 \% \\
4.26 \% \\
4.26 \%\end{array}$} & - Doctorate degree & $6 \%$ \\
\hline & & Average years practicing & \\
\hline & & as a physiotherapist & $15.36( \pm 10.66)$ \\
\hline & & Employment status & \\
\hline & & - Full-time & $81 \%$ \\
\hline \multicolumn{2}{|l|}{ Type of surgery } & - Part-time & $16 \%$ \\
\hline \multirow{6}{*}{$\begin{array}{l}\text { - Aware of the type of surgery } \\
\text { - Laminectomy with discectomy } \\
\text { - Laminectomy } \\
\text { - Microdiscectomy } \\
\text { - Discectomy } \\
\text { - Laminotomy }\end{array}$} & \multirow{2}{*}{$\begin{array}{l}85.11 \% \\
45 \%\end{array}$} & "- As needed" & $3 \%$ \\
\hline & & Practice setting & \\
\hline & $25 \%$ & - Private practice & $46 \%$ \\
\hline & $20 \%$ & - Hospital outpatient & $26 \%$ \\
\hline & $7.5 \%$ & - Acute care & $12 \%$ \\
\hline & $2.5 \%$ & - Home health & $6 \%$ \\
\hline \multirow{4}{*}{$\begin{array}{l}\text { Education } \\
\text { - High school } \\
\text { - Graduate degree } \\
\text { - Postgraduate degree }\end{array}$} & \multirow{4}{*}{$\begin{array}{l}53 \% \\
32 \% \\
17 \%\end{array}$} & - Other & $10 \%$ \\
\hline & & Undergone spinal surgery & 4 physio- \\
\hline & & themselves & therapists \\
\hline & & & $(2.84 \%)$ \\
\hline \multicolumn{2}{|l|}{ Annual Income } & \multicolumn{2}{|l|}{ Formal Certification? } \\
\hline$-\$ 10-\$ 50000$ & $53 \%$ & - Yes & $24 \%$ \\
\hline$-\$ 50-100000$ & $33 \%$ & - No & $76 \%$ \\
\hline$->\$ 100000$ & $14 \%$ & & \\
\hline
\end{tabular}


treating the same postoperative patients $(\mathrm{p}=0.03)$.

- Activities, Mobility and Physiotherapy: Physiotherapists rated 4 out of the 5 questions as more important in being answered, compared to patients: return to work $(\mathrm{p}<0.01)$, starting driving $(\mathrm{p}<0.01)$, limitations with activities $(\mathrm{p}=0.04)$ and the exact content of postoperative physiotherapy $(\mathrm{p}<0.01)$.

- Pain and Physiotherapist experience: In 3 of the 4 pain questions, less experienced physiotherapists rated it more important to educate patients regarding pain, compared to more experienced physiotherapists including issues regarding resolving the preoperative pain $(\mathrm{p}=0.03)$, pain at the surgery site $(\mathrm{p}=0.12)$ and “other" pain $(\mathrm{p}<0.01)$. Seventy three percent of therapists indicated that they did not receive any training in their undergraduate programs in regards to spinal surgery rehabilitation.

- Pain, spinal surgery and pain science education: The majority of patients (74\%) indicated pain as the main indication for undergoing LSR, followed by numbness and pain (23.91\%). Forty-two percent of the patients indicated they were afraid the pain they were experiencing postoperatively would get worse. The majority of patients $(85 \%)$ indicated that they expected to have pain following surgery, while only $53 \%$ of the therapists indicated that their patients expected to have pain following LSR

(Figure 1).

\section{Education delivery methods}

Verbal one-on-one education was the preferred means of delivering preoperative education for patients and physiotherapists in this study. In all categories, patients indicated surgeons as the primary health care provider who should provide preoperative education. Ninety two percent of physiotherapists believed that preoperative education is more important than postoperative education with only $9 \%$ of physiotherapists providing preoperative education in a structured/formal program.

\section{DISCUSSION}

This is the first study to determine whether there is a demand for preoperative education for LSR.

The importance of preoperative education

Patients and physiotherapists regarded preoperative education for LSR as very important, concurring with studies in cardiology, general surgery and orthopedics (Asilioglu and Celik 2004; Lin and Wang 2005; McDonald et al 2004). Preoperative education in medicine is directed towards decreasing fear and anxiety associated with impending surgery (Asilioglu and Celik 2004; Lin and Wang 2005; McDonald et al 2004), which concurs with the results of this study. Decreased preoperative anxiety has been linked to a decrease in post-

Table 3: Ranking by patients and physiotherapists of the 5 most important issues in regards to preoperative education for lumbar spine surgery.

\begin{tabular}{|lll|lll|}
\hline $\begin{array}{l}\text { Patient } \\
\text { Rank }\end{array}$ & $\begin{array}{l}\text { Mean } \\
\text { Score }\end{array}$ & Question & $\begin{array}{l}\text { Patient } \\
\text { Rank }\end{array}$ & $\begin{array}{l}\text { Mean } \\
\text { Score }\end{array}$ & \begin{tabular}{l} 
Question \\
\hline 1
\end{tabular} \\
94.04 & $\begin{array}{l}\text { How important is it for you } \\
\text { to know the exact reason } \\
\text { for undergoing spinal } \\
\text { surgery? }\end{array}$ & 1 & 94.12 & $\begin{array}{l}\text { How important is it for your } \\
\text { patient to know about any } \\
\text { limitations about activities } \\
\text { such as bending, lifting, } \\
\text { walking and sitting? }\end{array}$ \\
\hline 2 & 93.23 & $\begin{array}{l}\text { How important is it for you } \\
\text { to know the risks associated } \\
\text { with the surgery? }\end{array}$ & 2 & 93.74 & $\begin{array}{l}\text { How important is it for your } \\
\text { patient to know the risks } \\
\text { associated with the surgery? }\end{array}$ \\
\hline 3 & 91.49 & $\begin{array}{l}\text { How important is it for you to } \\
\text { know about any limitations } \\
\text { about activities such as } \\
\text { bending, lifting, walking } \\
\text { and sitting? }\end{array}$ & 3 & 93.25 & $\begin{array}{l}\text { How important is it for } \\
\text { your patient to know the } \\
\text { alternatives to the surgical } \\
\text { procedure? }\end{array}$ \\
\hline 4 & $\begin{array}{l}\text { How important is it for you } \\
\text { to know how long it will take } \\
\text { to experience complete } \\
\text { loss of all pain? }\end{array}$ & 4 & 92.00 & $\begin{array}{l}\text { How important is it for your } \\
\text { patient to know the reason } \\
\text { for surgery? }\end{array}$ \\
\hline 5 & $\begin{array}{l}\text { How important is it for you } \\
\text { to know how much pain } \\
\text { before surgery will be gone } \\
\text { after surgery? }\end{array}$ & 5 & 91.41 & $\begin{array}{l}\text { How important is it for } \\
\text { your patient to know when } \\
\text { they can return to work } \\
\text { after surgery? }\end{array}$ \\
\hline
\end{tabular}


operative pain, increase in return to work rates and improved functional activities (Lin and Wang 2005; McDonald et al 2004). Physiotherapist's rating of preoperative education as more important than postoperative education may reflect that patients with persistent disability and pain following LSR are more likely to be sent to physiotherapy for rehabilitation (Ostelo et al 2003), exposing physiotherapists to higher numbers of patients with persistent pain following LSR.

\section{Information required in preoperative programs for spinal surgery patients}

Three main topics were identified for inclusion in a preoperative education program for LSR patients: Reason for surgery, risk of the surgery and limitations following surgery. Reason for surgery was rated as most important because patients want to know how their disability will be addressed by surgery (Toyone et al 2005). More than $70 \%$ of the patients underwent surgery for pain, with or without neurological impairment. It can thus be argued that patients rated the reason for surgery important to understand how surgery will alleviate their pain (Toyone et al 2005). Risks factors (second highest rated) may signify that an understanding of the risk of

Figure 1: Pain expectancies following spinal surgery.

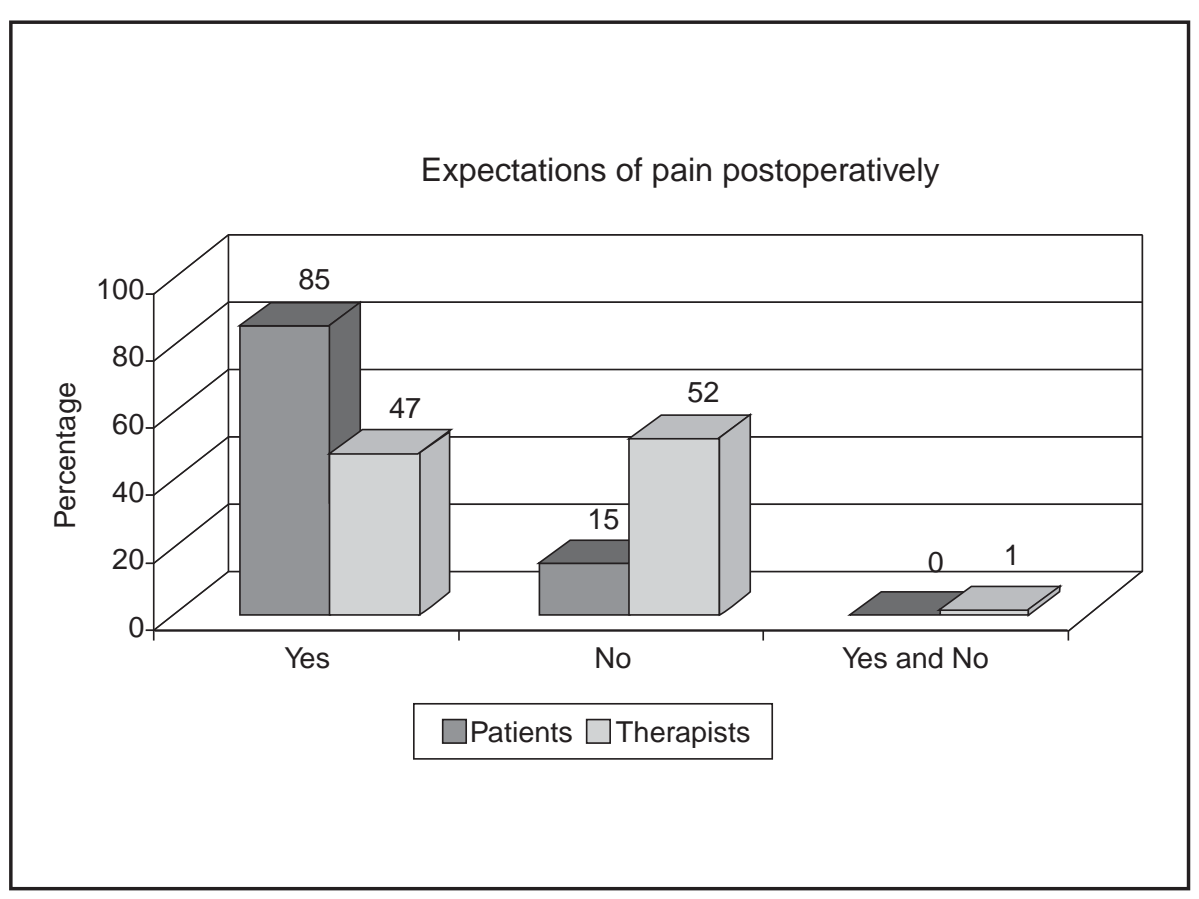

$37 \%$ percent felt they received adequate information on pain. Patients are interested in pain and should be educated more about pain (Moseley 2003). Pain science education for LBP has shown changes in pain beliefs and attitudes (Moseley et al 2004), improved cognition and physical performance (Moseley 2005; Moseley et al 2004), increased pain thresholds and improved outcomes from therapeutic exercise (Moseley 2003; Moseley 2005; Moseley et al 2004). Pain science education may also decrease fear and anxiety associated with spinal surgery, potentially resulting in better outcomes following LSR (Moseley 2003). Fear of pain is a powerful contributor to chronic ongoing pain states (Waddell and Burton 2005) and $50 \%$ of patients expressed fear and anxiety about their persistent pain and were afraid that their postoperative pain would worsen. Physiotherapists' interest in pain may be related to their own difficulty with treating pain, especially chronic pain (Latimer et al 2004; Moseley 2003). Seventy-three percent of therapists indicated that they did not receive any training in their undergraduate programs on spinal surgery rehabilitation, similar to studies highlighting the lack of pain science education in undergraduate training (Latimer et al 2004). Pain science education has been shown to ease student fears and increase knowledge in treating chronic pain (Latimer et al 2004) and physiotherapy programs should include pain science education as well as education on LSR.

\section{Educational delivery method}

Patients and physiotherapists preferred verbal one-on-one preoperative education, which concurs with other surgery studies (Hoermann et al 2001; Macario et al 2003) since it provides patients with a more interactive format and opportunity for seeking answers to questions. This is in contrast to booklets and the internet which show modest results at best (Barrett et al 2002) and may be only a means of covering medico-legal aspects (Turner and Williams 2002). Only $4 \%$ of patients chose the internet/ websites for preoperative education, which strengthens the argument of one-on-one education. 


\section{Study limitations}

This study was limited by a small patient sample size which only included decompressive surgeries applicable to lumbar radiculopathy, and only patients between the ages of 20 and 65 . Results may not be applicable to other spinal surgery populations, different etiologies and patients older than 65 or younger than 18 , as these patients may have different educational needs. The questionnaire used in this study was not tested for reliability.

\section{CONCLUSION}

Patients and physiotherapists believe there is a demand for the development of preoperative educational programs for LSR. Preoperative educational programs should include education on reasons for surgery, risks associated with surgery, limitations following surgery as well as education regarding pain expectations. Verbal one-on-one education was the preferred method of delivery of preoperative education for LSR. Future research should seek to determine if such preoperative programs produce superior outcomes.

\section{REFERENCES}

Asilioglu K, Celik SS 2004 The effect of preoperative education on anxiety of open cardiac surgery patients. Patient Education and Counseling 53:65-70.

Barrett PH, Beck A, Schmid K, Fireman B, Brown JB 2002 Treatment decisions about lumbar herniated disk in a shared decisionmaking program. Joint Commission Journal of Quality Improvement 28:211-9.

Deyo RA, Mirza SK 2006 Trends and variations in the use of spine surgery. Clinical Orthopedics and Related Research 443: 139-46.

Deyo RA, Mirza SK, Martin BI 2006 Back pain prevalence and visit rates: estimates from U.S. national surveys, 2002. Spine 31:2724-7.

Discovery, Statistics. 2006.

Gross AR, Aker PD, Goldsmith CH, Peloso P 2000 Patient education for mechanical neck disorders. Cochrane Database of Systematic Reviews CD 000962.

Hoermann S, Doering S, Richter R, Walter MH, Schussler G. [Patients' need for information before surgery]. Psychotherapie Psychosomatik Medizinische Psychologie 51:56-61.
Jette DU, Bacon K, Batty C, Carlson M, Ferland A, Hemingway RD, Hill JC, Ogilvie L, Volk D 2003 Evidence-based practice: beliefs, attitudes, knowledge, and behaviors of physical therapists. Physical Therapy 83:786-805.

Johansson K, Nuutila L, Virtanen H, Katajisto J, Salantera S 2005 Preoperative education for orthopaedic patients: systematic review. Journal of Advanced Nursing 50: 212-23.

Latimer J, Maher C, Refshauge K 2004 The attitudes and beliefs of physiotherapy students to chronic back pain. Clinical Journal of Pain 20:45-50.

Lin LY, Wang RH 2005 Abdominal surgery, pain and anxiety: preoperative nursing intervention. Journal of Advanced Nursing 51: 252-60.

Louw QA, Morris LD, Grimmer-Somers K 2007 The prevalence of low back pain in Africa: a systematic review. Biomed Central Musculoskeletal Disorders 8:105

Lurie JD, Birkmeyer NJ, Weinstein JN 2003 Rates of advanced spinal imaging and spine surgery. Spine 28:616-20.

Macario A, Schilling P, Rubio R, Bhalla A, Goodman S 2003 What questions do patients undergoing lower extremity joint replacement surgery have? Biomed Central Health Services Research 3:11.

McDonald S, Hetrick S, Green S 2004 Pre-operative education for hip or knee replacement. Cochrane Database of Systematic Reviews CD003526.

Moseley GL 2003 A pain neuromatrix approach to patients with chronic pain. Manual Therapy 8:130-40.

Moseley GL 2005 Widespread brain activity during an abdominal task markedly reduced after pain physiology education: MRI evaluation of a single patient with chronic low back pain. Australian Journal of Physiotherapy 51:49-52.

Moseley GL, Nicholas MK, Hodges PW 2002 A randomized controlled trial of intensive neurophysiology education in chronic low back pain. Clinical Journal of Pain 20:324-30.

Moseley L 2002 Combined physiotherapy and education is efficacious for chronic low back pain. Australian Journal of Physiotherapy 48:297-302.

Murray CJ, Lopez AD 1997 Global mortality, disability, and the contribution of risk factors: Global Burden of Disease Study. Lancet 349:1436-42.
Onesti ST 2004 Failed back syndrome. Neurologist 10:259-64.

Ostelo RW, de Vet HC, Waddell G, Kerckhoffs MR, Leffers P, van Tulder M 2003 Rehabilitation following first-time lumbar disc surgery: a systematic review within the framework of the cochrane collaboration. Spine 28:209-18.

Toyone T, Tanaka T, Kato D, Kaneyama R, Otsuka M 2005 Patients' expectations and satisfaction in lumbar spine surgery. Spine 30:2689-94.

Turner P, Williams C 2002 Informed consent: patients listen and read, but what information do they retain? New Zealand Medical Journal 115:U218.

Udermann BE, Spratt KF, Donelson RG, Mayer J, Graves JE, Tillotson J 2004 Can a patient educational book change behavior and reduce pain in chronic low back pain patients? The Spine Journal 4:425-35.

Waddell G, Burton AK 2005 Concepts of rehabilitation for the management of low back pain. Best Practice and Research: Clinical Rheumatology 19:655-70. 